\title{
FROM THE HEAD AND THE HEART: LOCATING COGNITION- AND AFFECT-BASED TRUST IN MANAGERS' PROFESSIONAL NETWORKS
}

\author{
ROY YONG JOO CHUA \\ PAUL INGRAM \\ MICHAEL W. MORRIS \\ Columbia University
}

\begin{abstract}
This article investigates the configuration of cognition- and affect-based trust in managers' professional networks, examining how these two types of trust are associated with relational content and structure. Results indicate that cognition-based trust is positively associated with economic resource, task advice, and career guidance ties, whereas affect-based trust is positively associated with friendship and career guidance ties but negatively associated with economic resource ties. The extent of embeddedness in a network through positive ties increases affect-based trust, whereas that through negative ties decreases cognition-based trust. These findings illuminate how trust arises in networks and inform network research that invokes trust to explain managerial outcomes.
\end{abstract}

A central insight of organizational research is that managers rely on networks of relations for the resources, information, and support needed for career and business success (Coleman, 1988; Lin, 1999; Seibert, Kraimer, \& Liden, 2001). As businesses evolve toward flatter structures and more fluid boundaries, the professional networks that managers develop become even more important. Trust, or the willingness to make oneself vulnerable to another person despite uncertainty regarding motives and prospective actions (Kramer, 1999; Mayer, Davis, \& Schoorman, 1995; McAllister, 1995; Rotter, 1967), is often implicated when relationships in a network involve the exchange of valuable resources. Trust can foster greater cooperation (e.g., Coleman, 1990; Dawes, 1980; Messick \& Brewer, 1983) and richer information exchange (Uzzi, 1996) than would otherwise occur. These benefits of trust are frequently invoked in network theorizing to account for network effects on important managerial outcomes such as job mobility (Podolny \& Baron, 1997), job satisfaction (Helliwell, 2005), and knowledge sharing (e.g., Abrams, Cross, Lesser, \& Levin, 2003).

Despite the pivotal role of trust in network theorizing, there has been relatively little empirical research on what types of trust managers place in members of their professional networks and where in those networks these types of trust are most likely to occur. Only a few studies have explicitly measured managers' experienced trust in their networks of professional relationships (e.g., Farh, Tsui, Xin, \& Cheng, 1998; Ferrin, Dirks, \& Shah, 2006; Levin \& Cross, 2004). Furthermore, although other areas of organizational and social science research have distinguished among the qualitatively different bases on which trust develops (Kramer, 1999; Lewicki \& Bunker, 1996; Lewis \& Weigert, 1985; Zucker, 1986), these distinctions have rarely been integrated into network research.

In the present research, we begin to redress this gap by applying the basic distinction between trust from the head versus trust from the heartthat is, cognition-based versus affect-based trust (McAllister, 1995). Specifically, we examine the extent to which these two types of trust are associated with (1) the relational content of the ties that make up a professional network and (2) an individual's embeddedness in positive and negative ties to the other members of a manager's network. By examining how managers place trust in others-from the head or the heart-we hope to make several contributions. First, the distinction between cognition- and affect-based trust calls to attention two distinct systems of social psychological processes. Whereas cognitionbased trust involves a calculative and instrumental assessment, affect-based trust involves empathy, rapport, and self-disclosure. These processes of trusting differ experientially and have distinct antecedents and consequences (Drolet \& Morris, 2000; Kramer, 1999; McAllister, 1995). We develop a method to capture these qualitatively different types of trust and illuminate their different 
associations with various properties of social networks. ${ }^{1}$

Second, we hope to provide a service to researchers who study specific types of networks (e.g., friendship or task advice networks). Different types of network ties are akin to the different types of networks that managers maintain. By elucidating how the two types of trust depend on the varying content of network ties, we can gain a more nuanced understanding of exchange relationships in professional networks. Our research can therefore inform network researchers as to when they can assume the presence of what type of trust in the specific networks they study.

Third, a more detailed understanding of trust in social networks would enable researchers to build more precise theories. Recent research has shown that cognition- and affect-based trust can lead to different outcomes (Levin \& Cross, 2004; McAllister, 1995; Ng \& Chua, 2006). Therefore, network researchers who make further distinctions between the types of trust, as opposed to treating it as a unidimensional construct, could make more precise predictions.

\section{THEORY DEVELOPMENT AND HYPOTHESES}

\section{Cognitive and Affective Bases of Trust}

It is widely acknowledged that trust arises through distinct psychological processes (Kramer, 1999; Lewicki \& Bunker, 1996; Lewis \& Weigert, 1985; McAllister, 1995; Zucker, 1986). A central distinction is that between cognition- versus affect-based trust (McAllister, 1995). Cognition-based trust refers to trust "from the head," a judgment based on evidence of another's competence and reliability. It is an instrumental inference that one makes from information about the other's behavior under specific circumstances. By contrast, affect-based trust refers to trust from the heart, a bond that arises from one's own emotions and sense of the other's feelings and motives. With affect-based trust, individuals express care and concern for the welfare of their partners and believe in the intrinsic virtue of such relationships (Rempel, Holmes, \& Zanna, 1985). This type of trust usually involves emotional

\footnotetext{
${ }^{1}$ We thank an anonymous reviewer for the observation that some network research treats trust networks as a distinct type of network. These previous attempts to measure trust in networks using a distinct name generator have been methodologically limited to capturing only a single type of trust. In our present research, we treat trust as a psychological state that has different bases and could arise in different types of network ties.
}

investment and is more enduring and generalizable over situations than is cognition-based trust (Lewicki \& Bunker, 1996; Lewis \& Weigert, 1985). These two types of trust align with the broader distinction in social psychology between two basic dimensions on which people map others, competence and warmth (Fiske, Cuddy, \& Glick, 2007).

The distinction between cognition- and affectbased trust has received considerable empirical support (Fryxell, Dooley, \& Vryza, 2002; Holste \& Fields, 2005; Levin \& Cross, 2004; Lewicki \& Bunker, 1996; McAllister, 1995; Ng \& Chua, 2006; Webber \& Klimoski, 2004; Wilson, Straus, \& McEvily, 2006). In a field study of managers, McAllister (1995) found that ratings of many trust-related items reduced to two factors rather than one in a confirmatory factor analysis. Laboratory studies have yielded findings consistent with the McAllister study (e.g., Ng \& Chua, 2006). Moreover, the two types of trust are differentially related both to consequences, such as forms of organizational citizenship and cooperative behavior (McAllister, 1995; $\mathrm{Ng} \&$ Chua, 2006), and to flows of tacit knowledge (Levin \& Cross, 2004).

Drawing on this evidence, we argue that it is imperative to differentiate these two types of trust in network research. That is, if particular networks are theorized to be helpful because they generate trust, it is important to specify what type of trust it is and to empirically test the assumed associations. We expect that trust is associated with particular network properties but that these associations vary depending on the type of trust. We focus on the two basic properties identified in egocentric network research: the tie types or content of exchange within a relationship and the structure of interconnection surrounding a relationship (i.e., embeddedness).

We focus on these variables because network scholars agree that the two central concepts in network analysis are the structure of a network and the content (substance) of the dyadic ties among social parties (e.g., Burt, 1983; Freeman, 2004; Kilduff, Tsai, \& Hanke, 2006; Schweizer, 1997; Tichy, Tushman, \& Fombrun, 1979). For instance, Tichy et al. (1979) described the transactional content of network ties as elementary properties of social networks. Schweizer called the notion of embeddedness "central to the social networks perspective" (1997: 739). In their more recent review of the social network research paradigm, Kilduff et al. described the primacy of relations, or network ties, as "the most regularly invoked difference between network research and conventional social science research" (2006: 1034). They also described embeddedness as a key concept in network research.

The content of network ties and embeddedness 
are also especially relevant to trust and the basis on which it develops. In their professional lives, managers maintain different types of network ties to obtain different resources (e.g., task advice or friendship support). Some of these network ties are instrumental in nature, whereas others are more socio-emotional or expressive (Lincoln \& Miller, 1979). This diversity of network ties lends itself well to the investigation of the different ways that managers trust their network members. As for embeddedness, the relevant literature identifies trust as an important mechanism behind its influence (e.g., Uzzi, 1996; Uzzi \& Gillespie, 2002).

In developing our hypotheses, we began by considering how managers' trust depends on the content of their ties to their network members. We then examined how trust depends on the network members' embeddedness in managers' networks. Throughout this study, we framed our hypotheses in terms of how trust is associated with the network variables, although we acknowledged the possibility of a different causal direction. Our goal was to clarify the ways managers trust others in their networks, not necessarily to pinpoint the causal antecedents of trust. In particular, one key objective of this research was to identify where in networks different types of trust occur. We nevertheless consider the issue of causal direction in more detail below in our Discussion section. Also, for clarity of exposition throughout this article, we adopt the network research convention of referring to a focal individual as "ego" and to his or her network members as "alters."

\section{Types of Trust and Relational Content}

We first consider how an ego trusts alters connected by four different types of social exchanges in professional networks, namely (1) friendship and social support, (2) task advice, (3) economic and financial support, and (4) mentoring and career guidance. We chose to examine these network ties because they are common exchange relationships in managers' professional lives. Various prior network research studies have also examined one or more of these ties (Gibbons, 2004; Gibbons \& Olk, 2003; Ingram \& Roberts, 2000; Larson, 1992; McGrath, Vance, \& Grey, 2003; Sparrowe \& Liden, 2005). We discuss each type of network tie separately and analyze its unique effects on trust, although the tie types are by no means mutually exclusive (e.g., ties of friendship and task advice can run to the same alter). In fact, given that managers' network ties are often multiplex (i.e., multiple types of tie connect ego and alter), we hope to unpack the content of these network ties and show how different tie content is differentially associated with cognition- and affect-based trust.

Friendship ties. As managers pursue their careers, they often forge friendship ties. Friendship between two individuals typically starts with interpersonal attraction (Carley, 1991; Verbrugge, 1977) and grows with increased interaction. At the dyadic level, friendship enhances cooperation, encourages resource sharing (Krackhardt \& Stern, 1988), and facilitates open communication (Jehn \& Shah, 1997; Sias \& Cahill, 1998). Through friendship, individuals also find mutual care and concern, social comfort, and enjoyment (Bell \& Coleman, 1999; Suttles, 1970). These patterns of interpersonal interaction have been in turn linked to the development of emotional attachment (Brass, 1992), intimacy (Fehr, 2004; Wiseman, 1986), and altruistic behavior (Suttles, 1970).

Given that friendship embodies socio-emotional engagements and positive perceptions of another's motives, the presence of a friendship tie is especially likely to indicate affect-based trust. This is because the elements of friendship are the foundations upon which affect-based trust is built. Friends perceive each other as having their interests and welfare at heart (Suttles, 1970). This expectation of caring altruistic behavior fosters affect-based trust (McAllister, 1995; Rempel et al., 1985). The domaingeneral scope of friendship also suggests a fit to affect-based trust given that this type of trust generalizes over circumstances (Gibbons, 2004).

Although friendship in professional settings may also contain elements of cognition-based trust, such as a prior history of positive interactions, these elements are not specific to friendship relations (Gibbons, 2004). Certainly, professional competence and reliability are not necessary conditions for the development of friendship. Hence, we do not hypothesize a relationship between friendship ties and cognition-based trust.

Hypothesis 1. In a professional network, the presence of a friendship tie in which an ego gets friendship from an alter is positively associated with ego's affect-based trust in alter.

Task advice ties. A key function of managers' networks is to help them seek information and advice for problem solving (Gibbons, 2004; McGrath et al., 2003; Sparrowe \& Liden, 2005). Task advice ties are channels through which managers obtain resources such as information, assistance, and guidance related to the completion of their work (Cross \& Sproull, 2004; Sparrowe, Liden, Wayne, \& Kraimer, 2001). In professional networks, after an alter has provided an ego with useful taskrelated advice, ego is likely to identify this alter as 
someone who has the relevant expertise, competence, or experience in the given task domain (thus demonstrating cognition-based trust). Conversely, an ego is also more likely to seek task advice from an alter who is perceived to be reliable and competent because such an alter is more likely to provide useful assistance (Borgatti \& Cross, 2003; Hinds, Carley, Krackhardt, \& Wholey, 2000). For instance, Hinds et al. (2000) found that, when selecting work partners, individuals preferred those who had reputations for being competent. Holste and Fields (2005) showed that cognition-based trust predicted the use of information and knowledge from others. Hence, we expected the presence of a task advice tie to be positively associated with cognition-based trust.

However, alter's being a source of task advice to ego does not mean that a socio-emotional relationship will necessarily develop between them. The flow of task advice and information in a professional network can serve purely work purposes and lack exchanges on the personal level. Any social interactions between ego and alter are likely to be conducted at arm's length until the two become friends (Sias \& Cahill, 1998). Therefore, we do not predict any specific relationship between task advice ties and affect-based trust.

Hypothesis 2. In a professional network, the presence of a task advice tie in which an ego gets task advice from an alter is positively associated with ego's cognition-based trust in alter.

Economic resource ties. Managers sometimes seek economic resources from others in their networks, as a means to, for example, fund new projects or start business initiatives. Economists have long acknowledged that economic actions are influenced by the degree to which the involved parties trust each other (Akerlof, 1982; Williamson, 1993). This is because economic transactions carry risks and threats of exploitation. In economic transactions, the presence of trust can reduce the specification and monitoring of contracts, reduce uncertainty, and provide material incentives for cooperation (Hill, 1990). Parties in an economic exchange also have incentives to behave in a trustworthy manner if they expect to have future economic relations (Axelrod, 1984). This type of trust is calculative and instrumental, and hence cognition-based.

Cognition-based trust may further develop following positive economic transactions. For instance, after an alter has provided financial resources to help an ego achieve certain goals, ego is likely to view this alter as financially capable and as one whom he or she can rely on for such help in the future. As the economic interaction gets repeated, ego's confidence in the competence and economic value of alter also increases (Hite, 2005: 130). In sum, although the relationship between economic exchange and cognition-based trust is likely to be reciprocal and undoubtedly complex, theoretical and empirical evidence suggest that they are positively associated.

Hypothesis 3a. In a professional network, the presence of an economic resource tie in which an ego gets economic resources from an alter is positively associated with ego's cognitionbased trust in alter.

Conversely, we expected economic resource ties to have the opposite relationship with affect-based trust. Instrumentality and affect in the same relationship may undermine each other, as reflected in the aphorism "Never lend money to a friend." Indeed, Silver's (1990) analysis of the modern Western conception of friendship suggests that the very possibility of true affect depends on a separation from instrumental concerns. Although a precept of contemporary economic sociology is that affective concerns brace economic pursuits, they do not coexist effortlessly (Zelizer, 2005). For instance, Foa and Foa (1974) suggested that resources from different relational domains (e.g., money versus love) tend to be incommensurable. This tension has been recognized in the network literature. In their study of friendships between competing hotel managers, Ingram and Roberts (2000) found that managers were most likely to forge friendships when the instrumental value of those relationships was highest. At the same time, the authors reported that "while they [the hotel managers] had friends among other hotel managers, these were not their closest friends. The instrumental component probably limits them as vehicles for sentiment" (Ingram \& Roberts, 2000: 418).

The imposition of instrumentality on affect is probably greatest when economic resources are at stake. Unlike friendship and task advice, money is fungible and easily quantifiable. It is therefore more naturally the subject of specific exchange-the basis of instrumental relations, rather than of the generalized exchange upon which affective relations are built (Bearman, 1997; Flynn, 2005; Sahlins, 1972). Furthermore, to the extent that economic decisions often involve the maximization of selfgain, economic exchanges may reflect what Sahlins (1972) called "negative reciprocity," a type of reciprocity characterized by a high degree of self-interest and lack of concern for the other. Hence, managers are not likely to develop deep, positive, 
affective relationships with those whom they engage in economic exchanges, nor are they likely to view those to whom they are affectively close as sources of economic aid. This separation between instrumentality and affect should result in a negative association between economic-resource ties and affect-based trust.

Hypothesis $3 b$. In a professional network, the presence of an economic resource tie in which an ego gets economic resources from an alter is negatively associated with ego's affect-based trust in alter.

Career guidance ties. Career guidance, such as mentoring, is a complex form of social exchange because it combines instrumental and socioemotional elements (Clawson, 1980; Kram, 1985). Kram (1985) described mentoring as a set of roles and role functions that include coaching, support, and sponsorship. These functions can be broadly divided into two categories, psychosocial mentoring and career enhancement mentoring. With psychosocial mentoring, a mentor provides socioemotional support and encouragement. With career enhancement mentoring, the mentor imparts intellectual skills and knowledge and provides career opportunities and exposure for his or her protégé. Although traditionally older individuals provide mentoring, Kram and Isabella (1985) found that peers in an individual's social network could also offer mentoring.

In professional networks, when a given alter is a provider of useful career advice and opportunities to a given ego, two types of perceptions are invoked. First, ego is likely to perceive alter as having relevant experience, competence, and access to valuable information not available to him or her. This perception is the foundation of cognitionbased trust. Second, ego is also likely to perceive alter as genuinely caring about him or her, because alter is willing to provide career guidance and advice. Furthermore, alters who provide ego with career advice are also likely to provide socioemotional support, encouragement, and confirmation in times of need (Kram \& Isabella, 1985). As a result, ego develops affect-based trust in these alters. In sum, we argue that an ego is likely to have increased cognition- and affect-based trust in alters who provide him or her with career guidance information.

Hypothesis 4. In a professional network, the presence of a career guidance tie in which an ego gets career guidance from an alter is positively associated with ego's cognition- and affect-based trust in alter.

\section{How Do Managers Trust Embedded Network Members?}

The notion that trust in a dyadic relationship may be affected by the network structure that surrounds it is at the heart of the concept of embeddedness (Granovetter, 1985). Various researchers have concluded that interpersonal trust increases when a relationship is embedded in ties to third parties (Burt \& Knez, 1995, 1996; Coleman, 1988; Ferrin et al., 2006). However, these researchers have either inferred trust from the relationship between an ego and alter (Burt \& Knez, 1995) or relied on a unidimensional measure of trust (Ferrin et al., 2006).

We extend this line of research on embeddedness in two ways. First, we differentiate between cognition- and affect-based trust. Second, we further distinguish between positive embeddedness and negative embeddedness. By positive embeddedness, we refer to the extent to which an alter is connected to other alters by positive ties. These positive ties need not be affectively charged and can vary in strength. Examples range from friendship to cooperative formal working relationships. By negative embeddedness, we refer to the extent to which an alter is connected to other alters by negative ties. For example, two alters might dislike each other and intentionally avoid or even attempt to harm each other. Although negative relationships are relatively uncommon in networks, their rarity makes them especially salient (Labianca, Brass, \& Gray, 1998). Indeed, social psychological research has shown that negative information is given heavier weight and consideration than positive or neutral information because it represents potential threats or dangers (Rozin \& Royzman, 2001; Taylor, 1991). Negative relationships are important to consider because they represent the liability side of the social ledger and can affect organizational effectiveness (Jehn, 1995; Labianca \& Brass, 2006). Let us consider each form of embeddedness in turn.

Positive embeddedness. We propose that an alter's positive embeddedness is positively associated with an ego's affect-based trust in him or her. Recall that cognition-based trust is more instrumental and calculative, whereas affect-based trust is more socio-emotional. Dense networks have been shown to provide social support (House, Umberson, \& Landis, 1988; Kadushin, 1982; Mitchell \& Trickett, 1980; Polister, 1980; Stokes, 1985; Stokes \& Levin, 1986) and increase affect (Totterdell, Wall, Holman, Diamond, \& Epitropaki, 2004). These are conditions conducive to the development of affectbased trust. In addition, the more connected an alter is by positive ties to other alters in an ego's 
network, the greater is the level of perceived solidarity, the perception that alter is an integral part of ego's in-group (Kadushin, 1982; Wellman, 1988). With high positive embeddedness, the force of group identity and cohesiveness strengthens the socio-emotional bond with alter (Fiske \& Neuberg, 1990). Thus, ego should have higher affect-based trust in a densely embedded alter because such an alter is more likely to be perceived as having ego's welfare and interests at heart.

Is positive embeddedness also associated with cognition-based trust? To be sure, embeddedness can provide better monitoring of an alter's behaviors, thereby increasing alter's reliability. Positive feedback from other alters might also increase an ego's favorable perceptions of an alter. However, in the presence of a direct tie between ego and alter, ego's view of alter's reliability and competence should be primarily associated with alter's manifest skills and track record, as opposed to secondhand information or third-party monitoring. In other words, the degree to which alter is highly connected to ego's other network members by positive ties may not greatly affect alter's professional competence and reliability. Hence, although we predict that ego is likely to have affect-based trust in highly embedded alters, we do not make specific predictions regarding the relationship between positive embeddedness and cognition-based trust.

Hypothesis 5. The more embedded an alter is in an ego's network by positive ties, the higher ego's affect-based trust in alter.

Negative embeddedness. We propose that when a given alter is connected to other alters in an ego's network by negative ties (i.e., negative embeddedness exists), ego's trust in alter is undermined. This prediction is derived from balance theory (Heider, 1958, 1979), according to which relationships between the pairs in a triad are congruent. In other words, if A has positive relationships with $\mathrm{B}$ and $\mathrm{C}$, $B$ and $C$ should have a positive relationship with each other. If $\mathrm{B}$ and $\mathrm{C}$ have a negative relationship, A will have to reconsider his or her positive tie with one of them. Thus, the more a focal alter is connected by negative ties to other alters, the more difficult it becomes for ego to maintain a positive relationship with this focal alter (since other alters dislike him or her). As a result, ego's trust perceptions of the focal alter should be lower.

The negative association between negative embeddedness and trust is likely to apply to both cognition- and affect-based trust. Negative ties among alters can increase perceptions of intragroup conflict (Labianca et al., 1998) and decrease perceived group solidarity and cohesiveness, thereby reducing affect-based trust. Negative ties among alters can also lower ego's cognition-based trust in a focal alter because negative feedback or gossip obtained from other alters could undermine ego's otherwise positive perceptions of his or her reliability and competence. It is useful to note the asymmetric effect of third-party feedback. Positive information from third parties may not greatly influence ego's cognition-based trust in alter, but it is likely that negative information will. This is because negative information signals potential problems in future interactions with alter and thus stands out and weighs more heavily in ego's trust evaluations. ${ }^{2}$ Moreover, negative information is also disproportionately likely to be passed along to ego as it not only better serves the function of social vigilance but also makes for titillating gossip (Dunbar, 2004; Wert \& Solavey, 2004).

Hypothesis 6. The more embedded an alter is in an ego's network by negative ties, the lower ego's cognition- and affect-based trust in alter.

\section{METHODS}

\section{Research Setting and Participants}

We tested the above hypotheses using egocentric network data collected from managers attending executive MBA courses at a large East Coast university in the United States. A total of 101 managers (76 percent males) participated in this study. Of these, 71 percent were European/North American, 10 percent were East Asian, and the rest were of other ethnic groups (e.g., Indians, African Americans, and Latin Americans). The mean age of these participants was 35 . The most common industries of employment were finance and banking (22\%), information technology $(20 \%)$, and consulting $(17 \%)$. Typically, the participants held managerial positions in large companies. For example, vice presidents and managing directors at internationally known financial institutions and managers at prominent consulting firms were common in our sample. Other participants held executive positions in smaller companies (e.g., one was the CEO of a family printing business).

\footnotetext{
${ }^{2}$ Burt and Knez $(1995,1996)$ found that both positive and negative information obtained from third parties could influence trust but the effect of negative information was much stronger. However, these researchers did not differentiate between the bases of trust.
} 


\section{Procedures}

Participants completed a network survey as part of their course requirement. The survey allowed participants (egos) to list up to 24 individuals (alters) whom they deemed as significant members of their professional networks. The exact wording was, "List anyone that you feel is a significant part of your professional network. One way to identify these people is to go through your address book, and ask 'is this person significant in my professional network?' If you have more than 24 significant contacts, list the most significant 24." The alters listed could come from any context, including but not restricted to a participant's workplace. This name generator is suitable for examining both cognition- and affect-based trust in professional networks because the network members listed this way are likely to provide either instrumental or socio-emotional resources, sometimes both. By not explicitly instructing participants to think about any particular type of network tie at this stage, we hoped to first capture the most significant individuals in these managers' networks before further examining the managers' relationships with them.

For each alter listed, participants were asked to furnish details on their relationships, including the types of ties they maintained with these individuals, demographic differences, frequency of interaction, and relationship duration. Participants were also asked to indicate whether there were any relationships (positive or negative) among the alters they listed.

\section{Measures}

Cognition- and affect-based trust. We adapted measures of cognition- and affect-based trust from McAllister's (1995) study to suit the current research context. For cognition-based trust, participants indicated, on a scale ranging from 1, "not at all," to 5, "to a great extent," the extent to which they could rely on each listed contact to (1) complete a task that he or she had agreed to do for the participant and (2) have the knowledge and competence needed to get tasks done. We chose these items because they directly reflect the reliability and competence aspect of cognition-based trust; their factor loadings as reported in McAllister's study were also high (above .80). The correlation between these two items is .55. For affect-based trust, participants indicated on the same five-point scale the extent to which they felt comfortable going to each listed contact to (1) share their personal problems and difficulties and (2) share their hopes and dreams. We chose these items because they had the highest factor loadings on McAllister's trust scale (above .80) and were relevant in our research context of professional networks. These items captured the extent to which a participant was willing to be vulnerable to the contacts through discussion of personal issues. The correlation between these two items was .70. Practical constraints prompted our use of two items for each type of trust ${ }^{3}$ instead of McAllister's entire trust scale. Network surveys are repetitive because participants have to answer the same questions as many times as the number of contacts listed. We wanted to limit the tedium of the survey by being as parsimonious as possible with the trust measures.

Results of a multilevel confirmatory factor analysis (CFA) using structural equation modeling (LISREL 8.80) supported the notion that cognitionand affect-based trust represent two distinct dimensions of trust. Specifically, a two-factor model $\left(\chi^{2}=\right.$ $49, d f=5$; RMSEA $=.09)$ fitted our data significantly better than a one-factor model $\left(\chi^{2}=435\right.$, $d f=4$; RMSEA $=.32$ ). The estimated correlation between the two factors was .38. Given the clear factor structure, we used the average scores for each type of trust as the dependent variables in the analyses.

Types of network ties. To assess the content of network ties that connect participants and their network members, we asked participants to indicate in the network survey which of the following resources were obtained from each network member: (1) friendship and social enjoyment, (2) information or advice for getting tasks done, (3) economic resources, and (4) information on career guidance and opportunities. The specific wording was, "Which of these resources do you receive from your relationship with this person?" Participants could select multiple types of resources. The content of network ties was captured with dummy codes ( 1 if the specific form of resource was obtained from alter and 0 otherwise).

\footnotetext{
${ }^{3}$ In our larger program of research, we conducted a similar network survey but included the full trust scales adapted from McAllister (1995). The participants were 56 MBA students from the same university. We found that correlations between the two-item trust scales and the full trust scales were extremely high: .97 for affectbased trust and .95 for cognition-based trust. Factor loadings for the four items used in the present research were also high (above .90). Cronbach's alpha for the full affectbased trust scale was .96 and that for the full cognitionbased trust scale was .90. This provides further confidence that our present trust measures adequately capture the two trust constructs.
} 
Alter's embeddedness. The second part of our survey began with the heading "Who knows whom in your network?" Participants filled in a halfmatrix indicating the relationships between the alters they had listed in the first part of the survey. We captured both positive and negative relationships, instructing participants as follows: "A positive relationship can be (a) a close relationship (example: when people work very close together or have a high level of friendship ) or (b) a positive but not especially close relationship (example: people who know each other but are not in frequent contact, and are not strong friends or enemies)." We also told participants that "negative relationships exist between individuals that dislike each other, and intentionally avoid contact, or even attempt to harm each other."

Alter's positive ${ }^{4}$ (or negative) embeddedness was the number of observed positive (or negative) ties that existed between a given alter and the other network members divided by the total number of possible ties that this alter could have with these other members (excluding alter's tie to ego).

\section{Control Variables}

Network size. Network theories commonly rest on an assumption that an individual has a given relational capacity and that the cognitive and emotional costs of maintaining relationships limit the number of relationships any individual can effectively maintain (e.g., Granovetter, 1973). In our context, it was possible that individuals might have some limits to their capacity to add trusted others to their networks. Conversely, larger networks might engender trust by providing egos with more relational experience. For these reasons, we controlled for ego's network size, which was operationalized as the total number of listed contacts in each participant's network.

Relationship duration. It is likely that the longer an ego has known an alter, the higher his or her trust in the alter is. This variable was measured as the number of years ego had known each alter.

Frequency of interaction. The more often an ego interacts with an alter, the more ego learns about alter's competence and reliability (Burt, 2005); stronger relational bonds are also forged. Hence,

\footnotetext{
${ }^{4}$ In our data collection, we differentiated between two types of positive ties between alters: positive and close versus positive but not especially close. We combined them in computing positive embeddedness because, in our analysis, their respective effects on both types of trust were not statistically different.
}

frequency of interaction should have direct, positive impact on both cognition- and affect-based trust. We measured frequency of interaction as how often ego talked to each alter. Participants selected one of these options for each contact listed: "daily," "weekly," "monthly," and "not often." The responses were recoded into a single variable in which 4 represented daily interaction and 1 represented infrequent interaction.

Other alter characteristics. We captured alter's professional rank with respect to ego using three indicators. Participants indicated on the network survey whether each alter was of higher, the same, or lower rank than themselves. These indicators were then recoded into two dummy variables, higher rank and lower rank. "Same rank" was the omitted category in the analysis. We also captured alter's location with respect to ego's organization using three indicators: whether alter was in ego's work unit, not in ego's work unit but in ego's organization, or outside ego's organization. These indicators were then recoded into two dummy variables: "alter in same work unit as ego" and "alter in different organization from ego." The third category was the omitted category in the analysis.

We controlled for ethnic and gender differences between ego and alter because demographic differences could influence trust development. Two dummy indicators were used to denote whether ego differed from alter in ethnicity or gender (coded 1 if there was a difference, 0 otherwise). Given that our participants were mostly male North Americans or Europeans, we also included dummy indicators to represent whether ego was North American/European ( 1 if yes, 0 otherwise) and male ( 1 for male and 0 for female).

Ego's industry and job function. Our participants came from different industries and held different jobs. It is plausible that specific types of network ties are more prevalent in certain industries or jobs; for example, economic resource ties may be more common in finance. Such systematic differences could influence our results. To control for possible industry and job function effects, we obtained descriptions of the participants' jobs from the class "face book" and coded them into eight main industries ("finance/banking," "consulting," "consumer products," "medicine/pharmaceutical," "media," "manufacturing," "information technology," and "other") and eight main job functions ("finance/accounting," "sales/marketing," "operations," "general management," "information technology," "business development," "research and development," and "other"). Dummy indicators for these categories were entered as controls in the 


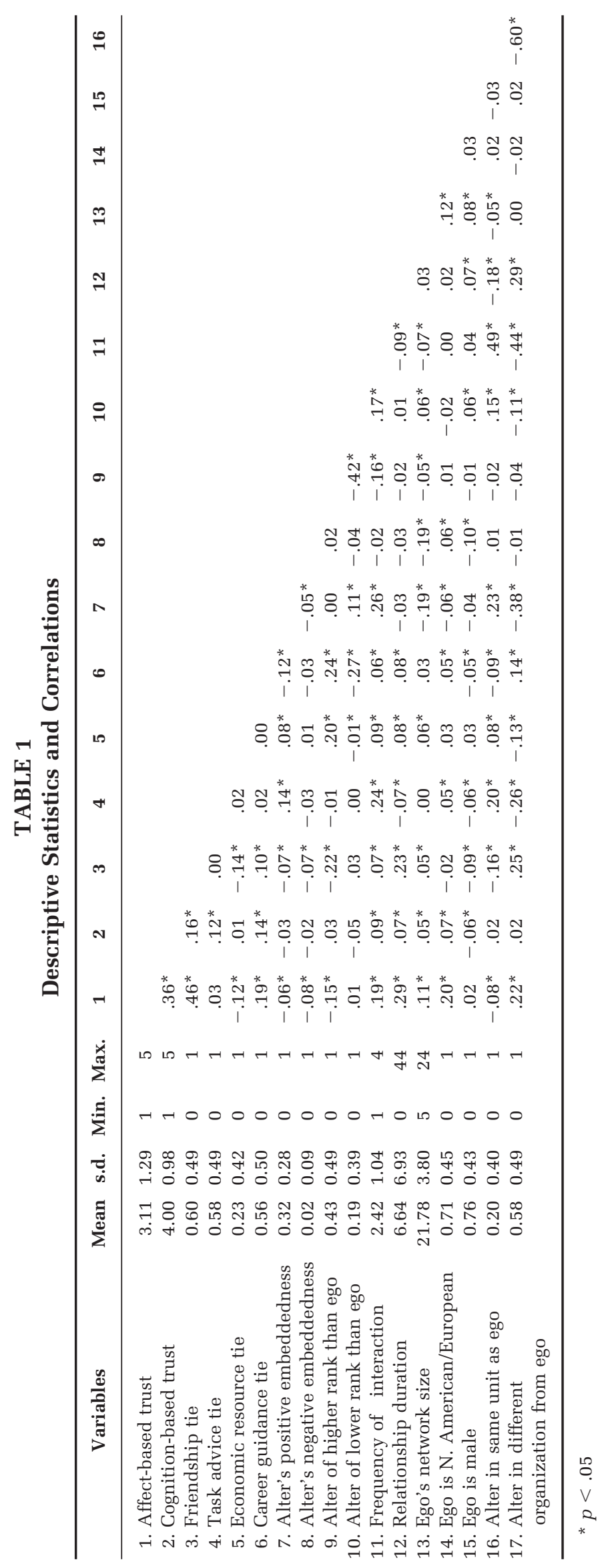


analysis. For both the industry and function indicators, "other" was the omitted category.

\section{Analytical Strategy}

Our theory and data involved hierarchically nested variables: up to 24 ego-alter relationships were nested within a given ego. Trust, our dependent variable, was conceptualized at the ego-alter level and measured unidirectionally; that is, we only assessed the extent to which ego trusted alter and not the extent to which alter trusted ego. Other variables, such as network size, were higher-level constructs and were measured at the aggregate network level for each ego.

A methodological concern was the nonindependence of observations, as each ego was associated with up to 24 alters. Individual-level analyses that do not control for the nested structure of data may misrepresent the effects within a given network (Klein, Dansereau, \& Hall, 1994). We considered fixed- and random-effects models, two common alternatives for controlling for the influence of a given ego on multiple observations (Hausman, Hall, \& Griliches, 1984). Both approaches allow estimatation of dyad-level effects within egocentric networks (Hoffman, Griffin, \& Gavin, 2000). In our analyses, these approaches yielded comparable results. We report results from random-effects models because these allow estimates for substantively interesting aggregate network variables such as network size. Random-effects models require the assumption that the random error associated with each unit (each ego) is not correlated with other regressors. We tested this assumption using Hausman's (1978) test and found it valid for both the analyses of cognition- and affect-based trust. Prior egocentric network research has used similar analytical strategies to address the problem of data nonindependence (e.g., Cross \& Sproull, 2004).

\section{RESULTS}

Table 1 shows the descriptive statistics and bivariate correlations among the key variables. Because the two types of trust are positively correlated at .36 $(p<.05)$, we controlled for the other type of trust when a given type of trust was the dependent variable. Table 2 reports the regression results. Models 1 to 3 present the analyses of affect-based trust, and models 4 to 6 present the analyses of cognitionbased trust.

We first considered the network tie predictions, Hypotheses 1 to 4, before examining the embeddedness effects, Hypotheses 5 and 6. In models 1 and 4, we entered only the control variables. Model 2 adds the network tie predictors into the regression for which affect-based trust is the dependent variable, whereas model 5 adds the same set of predictors into the regression for which cognition-based trust is the dependent variable. Results in model 2 show that affect-based trust is significantly higher in the presence of a friendship tie $(b=0.87, p<.01)$, supporting Hypothesis 1. There is no significant relationship between a friendship tie and cognitionbased trust ( $b=0.03$, n.s.). Consistently with Hypothesis 2, model 5 indicates that cognition-based trust is positively associated with the presence of a task advice tie between ego and alter $(b=0.23, p<.01)$. There is no significant relationship between a task advice tie and affect-based trust ( $b=0.05$, n.s.), as shown in model 2.

Hypotheses 3a and $3 \mathrm{~b}$ respectively propose that economic resource ties are positively associated with cognition-based trust but negatively associated with affect-based trust. The results support these hypotheses, as the economic resource tie variable has a positive coefficient in the analysis of cognition-based trust $(b=0.07, p<.05)$ and a negative coefficient in the analysis of affect-based trust ( $b=-0.18, p<.01$ ). We also found support for Hypothesis 4 in that both cognition-based trust $(b=0.14, p<.01)$ and affect-based trust $(b=0.27$, $p<.01)$ are positively associated with the presence of a career guidance tie.

Next, we entered the embeddedness predictors into models 3 and 6 . Results in model 3 indicate a positive relationship between alter's positive embeddedness and affect-based trust $(b=0.23, p<$ .05), supporting Hypothesis 5. However, alter's negative embeddedness has no effect on affectbased trust ( $b=0.01$, n.s.). Model 6 indicates that alter's negative embeddedness has a negative effect on cognition-based trust ( $b=-1.20, p<.01)$. Overall, there is partial support for Hypothesis 6. Positive embeddedness has no effect on cognitionbased trust ( $b=-0.14$, n.s.).

\section{DISCUSSION}

Although trust plays a central role in network theorizing, its constituent elements have seldom been directly examined in network research. To bridge this gap, we examined patterns of trust in professional networks. We found that not only do managers trust network members differently depending on the content of network ties, but also that differences exist in how each type of trust is associated with different forms of embeddedness. Specifically, managers have more affect-based trust in network members who are friends, sources of career guidance, or densely embedded in their net- 
TABLE 2

Results of Random-Effects Regression Analyses on Affect- and Cognition-Based Trust ${ }^{a}$

\begin{tabular}{|c|c|c|c|c|c|c|c|}
\hline Variables & Model 1 & Model 2 & Model 3 & Model 4 & Model 5 & Mode & el 6 \\
\hline Intercept & $-0.69^{*}(0.35)$ & $-0.56^{*}(0.33)$ & $-0.75^{*}(0.35)$ & $2.54 * *(0.31)$ & $2.46 * *(0.31)$ & $2.71^{* *}$ & $(0.32)$ \\
\hline \multicolumn{8}{|l|}{ Control } \\
\hline Affect-based trust & & & & $0.22 * *(0.02)$ & $0.21 * *(0.02)$ & $0.21 * *$ & $(0.02)$ \\
\hline Ego's network size & $0.03 * *(0.01)$ & $0.02 *(0.01)$ & $0.03^{*}(0.01)$ & $0.02^{*}(0.01)$ & $0.02 *(0.01)$ & 0.01 & $(0.01)$ \\
\hline Ego is N. American/European & $0.41 * *(0.14)$ & $0.42 * *(0.13)$ & $0.43 * *(0.13)$ & $-0.18 \quad(0.13)$ & -0.20 & $-0.19^{*}$ & $(0.13)$ \\
\hline Ego is male & $-0.22 \quad(0.14)$ & $-0.07 \quad(0.13)$ & $-0.06 \quad(0.13)$ & $-0.22^{*}(0.13)$ & -0.19 & -0.19 & $(0.13)$ \\
\hline Relationship duration & $0.04^{* *}(0.00)$ & $0.03 * *(0.00)$ & $0.03 * *(0.00)$ & $0.00 \quad(0.00)$ & $(0.00)$ & 0.00 & $(0.00)$ \\
\hline Frequency of interaction & $0.40 * *(0.03)$ & $0.32 * *(0.02)$ & $0.31 * *(0.02)$ & $0.05 * *(0.02)$ & $0.04 * \quad(0.02)$ & $0.04^{*}$ & $(0.02)$ \\
\hline Alter of different race than ego & $-0.14^{*}(0.06)$ & $-0.10^{*}(0.06)$ & $-0.10^{*}(0.06)$ & $0.07 \quad(0.04)$ & $0.07 \quad(0.05)$ & 0.06 & $(0.06)$ \\
\hline Alter in different organization & $0.61 * *(0.06)$ & $0.38 * *(0.06)$ & $0.41 * *(0.06)$ & -0.03 & -0.01 & -0.02 & $(0.05)$ \\
\hline
\end{tabular}

Key predictors

Friendship tie (Hypothesis 1)

Task advice tie (Hypothesis 2)

Economic resource tie

(Hypotheses 3a and 3b)

Career guidance tie (Hypothesis 4)

Alter's positive embeddedness

(Hypothesis 5)

Alter's negative embeddedness

(Hypothesis 6)

$$
\begin{aligned}
& 0.87^{* *}(0.05) \quad 0.87 * *(0.05) \\
& \begin{array}{llll}
0.05 & (0.05) & 0.05 & (0.05)
\end{array} \\
& -0.18^{* *}(0.05)-0.19^{* *}(0.05) \\
& 0.27 * *(0.05) \quad 0.27 * *(0.05) \\
& 0.23 *(0.11) \\
& 0.01 \quad(0.41)
\end{aligned}
$$

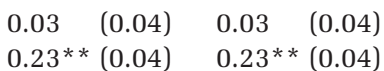$$
0.07 \text { * }(0.04) \quad 0.08^{*}(0.04)
$$$$
0.14 \text { ** }(0.04) \quad 0.14 * *(0.04)
$$$$
-0.14(0.10)
$$$$
-1.20^{* *}(0.04)
$$

$R^{2}$

$\Delta \chi^{2 \mathrm{~b}}$

\author{
0.35
}

$1,128.58^{* *}$
0.46
$384.38^{* *}$
0.46
$3.84^{\mathrm{C}}$
0.14
$374.86^{* *}$
0.17
$57.74^{* *}$
0.18

$13.13^{* *}$

${ }^{a}$ The number of dyadic observations is 2,043. Coefficients are unstandardized. Standard errors are reported in parentheses. Control variables for industry and job function are not presented to conserve space. We used dummy coding, and there are seven indicators for each of these two variables (eight categories per variable).

b The chi-square changes for models 1 and 4 are derived from comparing the given model with a constant-only model.

${ }^{\mathrm{c}}$ The chi-square change for adding only alter's positive embeddedness to model 2 is 3.83 ( $p=.05$ ).

${ }^{*} p<.05$

$* * p<.01$

works by positive ties. When a network member is a source of economic assistance, managers' affectbased trust in him or her actually decreases. Cognition-based trust, on the other hand, is higher in those who provide task advice, economic assistance, or career guidance. Whereas positive embeddedness has no effect on cognition-based trust, negative embeddedness reduces this type of trust.

\section{Theoretical Implications}

Our study has several theoretical implications for network research. First, we offer a more nuanced view regarding the existence of the different types of trust in social networks. In light of our findings, it appears that the common assumption that trust exists in networks ties that involve the exchange of valuable resources provides only part of the story. Sometimes network ties can be negatively associated with a type of trust. Our findings suggest, for instance, that when $\mathrm{A}$ is connected to B by an economic resource tie, the level of cognition-based trust between $A$ and $B$ is higher than it might be otherwise, but the level of affect-based trust is lower. Thus, network researchers studying economic exchange networks should be particularly careful when they invoke trust as part of their arguments. 
This provocative finding concerning the negative association between affect-based trust and economic resource ties also points to a fascinating tension that has so far been underplayed in the many applications of network theories to economic and organizational contexts. That is, economic relations undermine affect-based trust. This is not to say affect-based trust never exists in those relationships; clearly it does. Rather, our results suggest the opportunity for a shift in the theoretical attention of network theorists, from the implications of affect in economic contexts to the phenomenon of the very existence of such trust. The results here join efforts such as those of Silver (1990) and Zelizer (2005) in suggesting that the commingling of affect and economic exchange is not a "natural" occurrence, even if it is a common one. The question of how affect and instrumentality may coexist provides a rich opportunity to advance theories at the nexus of economy and society.

Our findings also highlight a difference between task advice and career guidance ties. Whereas task advice ties are positively associated with only cognition-based trust, career guidance ties are positively associated with both cognition- and affect-based trust. Therefore, it is important for researchers studying advice networks to clearly specify the type of advice in which they are interested. Although the provision of advice is generally associated with increased trust, how managers trust those who provide them with advice depends on its specific content.

The result that cognition- and affect-based trust are differentially associated with forms of embeddedness is also of notable theoretical importance. In the social network literature, the most prominent argument regarding the benefits of a dense network is that it provides social closure, which in turn increases trust among network actors (e.g., Burt \& Knez, 1995; Coleman, 1988). Although we generally agree with this assertion, our study suggests that the trust that is associated with a dense network composed by positive ties is socio-emotional in nature. In other words, actors believe that their densely embedded network members are trustworthy in that they belong to a closely knit group and thus have each other's interests and welfare at heart. Actors do not necessarily perceive their densely embedded network members as being more competent or reliable. This distinction is important when researchers invoke the argument that a dense network engenders trust. The validity of this argument depends on the type of trust and the associated outcomes of interest.

In addition, we extended prior research on embeddedness and trust by examining the effects of negative embeddedness. We hypothesized that negative embeddedness would reduce both types of trust but only found evidence that negative embeddedness reduces cognition-based trust. One explanation could be that positive and negative embeddedness exert opposite influences on affect-based trust but that positive embeddedness is much more prevalent and hence has a stronger effect. Indeed, only 14 percent of listed alters had some level of negative embeddedness, whereas 92 percent had some level of positive embeddedness. Conversely, because positive embeddedness is unlikely to influence cognition-based trust, the relationship between negative embeddedness and this type of trust becomes more pronounced.

Finally, our results can be used to interpret findings from prior research. Consider, for example, the study on Sydney hotels by Ingram and Roberts (2000). Those researchers examined the friendship networks of hotel managers and found evidence of collusion and customer sharing, two behavioral outcomes that depend on social cohesion and care and concern for each other. This finding is consistent with our finding that friendship ties are positively associated with affect-based trust. Yet among these hotel managers who were friends, there was not much evidence of knowledge sharing, a behavior that depends more on cognition-based trust, which is not a primary element in friendship networks.

\section{Practical Implications}

Recent research shows that trust in the workplace is an extremely valuable resource with a significant effect on job satisfaction and well-being (Helliwell, 2005). The negotiation literature also suggests that people are more willing to cooperate with those whom they trust (e.g., Drolet \& Morris, 2000). Hence, knowledge that can guide managers in developing trust in the workplace and in detecting trusting relationships among coworkers is likely to bring substantive benefits.

Our research has practical implications for building workplace trust. To build trust, managers have to first identify the gaps in trust in their networks. The associations between types of trust and exchange ties that we have identified is helpful for managers striving to understand the trust that exists in their networks. For example, if another person solely provides task advice to a focal person, then it is likely that the focal person's trust in the other is instrumental rather than affective. If the focal person primarily provides economic aid to the other person, then it is likely that the other's trust in the focal person comes from the head but 
not the heart. Such knowledge is particularly useful for managers who seek to strengthen their network ties. It informs them about types of trust that may be lacking in regions of their networks. It also tells them what kinds of ties to develop to foster the missing trust.

Furthermore, our research can help managers judge the type of trust that exists between pairs of other people, including their own network contacts. Trust between other people can be difficult to gauge as it is a subjective psychological state. Exchange relationships, on the other hand, are easier to see and can serve as cues for diagnosing the lines of trust. Knowledge regarding the associations between network ties and trust can therefore help managers better understand and influence the social dynamics among people around them.

\section{Limitations and Future Research Directions}

An inherent problem in cross-sectional analyses such as ours is determining the direction of causality. Reversed causality is more likely for our hypotheses regarding network ties than for those regarding embeddedness. In the latter set of hypotheses, the independent variables are not directly influenced by ego, so it is unlikely that they would be a result of ego's level of trust in alter. Conversely, it seems plausible that ego's trust in alter will affect the exchange relationship that ego and alter share. However, we are not particularly troubled by the likelihood of a complex causal relationship between the content of network ties and trust, because answering the question we set out to address in this study (i.e., How do managers trust their network members?) does not depend on a specific causal argument. Whether alter is a friend because she is trusted, trusted because she is a friend, or both, the evidence we present is nevertheless useful for locating trust in managers' networks.

Another limitation is common method bias, given that our data came from an egocentric survey (Podsakoff, MacKenzie, Lee, \& Podsakoff, 2003). For example, participants could have biased our results by basing their responses to the trust measures on certain implicit beliefs about network ties and trust. However, common method bias might not be a large problem for our study. Hypotheses 1 to 4 concern how four types of network ties influence two types of trust. Our predictions are in different, sometimes opposite, directions for a given type of trust (e.g., affect-based trust is negatively associated with economic resource ties but positively associated with career guidance ties). Common method bias, as an undifferentiated source of bias, is unlikely to explain our findings because participants would have to simultaneously consider eight implicit beliefs regarding tie type and trust (four types of ties times two types of trust) and complete the survey questions accordingly for our findings to emerge; this can be very challenging because different types of network ties can co-occur in different combinations. In fulfilling one implicit belief about how one type of trust should be related to a given type of tie, a participant could easily violate the implicit belief about another tie-trust relationship. Thus, it is highly unlikely that participants could have systematically biased the results.

The relationships between embeddedness and trust (Hypotheses 5 and 6) also cannot be easily explained by common method bias. Recall that embeddedness was computed from a half-matrix that participants completed after they listed all their network contacts. Given the large network size (an average of 22 contacts per participant), it is unlikely participants responded in a systematically biased manner so as to maintain consistency or fulfill some implicit belief about how the cell entries in the half-matrix should be related to the trust measures.

Our use of an egocentric approach, although common in network research, has other limitations. For instance, participants' recall of names is subject to bias, as is their recall of ties between alters (Kilduff \& Krackhardt, 1994). Future research that replicates our findings using a sociometric approach will be a valuable extension of our work.

Future research should also capitalize on our current set of findings to further explore how the two types of trust relate to other organizational variables. For instance, we found that managers trust network members of different ranks differently. The higher the rank of alters, the higher the cognition-based trust they engender (our regression coefficient was positive for "higher rank" and negative for "lower rank"). This finding is consistent with prior research indicating that higher-level jobs in organizations are usually associated with higher task discretion and high-trust psychological contracts (Fox, 1974; Nicholson \& Johns, 1985). For affect-based trust, however, there is a distinct negative effect only if alter outranks ego (the effect for "higher rank" is significant and negative, but there is no significant effect for "lower rank"). This notable asymmetry has implications for research on leader-member exchange (Graen \& Cashman, 1975). Trusting relationships between subordinates and bosses are more likely to be built on cognitive bases than affective bases.

Finally, although previous research has demonstrated that cognition- and affect-based trust may lead to different outcomes (e.g., McAllister, 1995), 
this effect has yet to be clearly demonstrated in network analyses. Recently, some work has began to differentiate the two types of trust in social network contexts (Levin \& Cross, 2004), but many questions remain unexplored. For instance, what implications does the finding that economic resource ties are positively associated with cognitionbased trust yet negatively associated with affectbased trust have on the way businesspeople engage in economic transactions with those in their networks? Does a manager's trust in an embedded network member depend on the specific content of the ties by which the network member is embedded? Furthermore, how do the two types of trust mediate structural variables such as network density and specific dyadic interactions between network actors? These are but some of the many interesting questions that derive from the recognition that there are different bases of trust located in different places in social networks.

\section{REFERENCES}

Abrams, L. C., Cross, R., Lesser, E., \& Levin, D. Z. 2003. Nurturing interpersonal trust in knowledge-sharing networks. Academy of Management Executive, 17(4): $64-77$.

Akerlof, G. 1982. Labor contracts as partial gift exchange. Quarterly Journal of Economics, 97: 543-569.

Axelrod, R. 1984. The evolution of cooperation. New York: Basic Books.

Bearman, P. 1997. Generalized exchange. American Journal of Sociology, 102: 1383-1415.

Bell, S., \& Coleman, S. 1999. The anthropology of friendship. Oxford, U.K.: Berg.

Borgatti, S. P., \& Cross, R. 2003. A relational view of information seeking and learning in social networks. Management Science, 49: 432-445.

Brass, D. J. 1992. Power in organizations: A social network perspective. In G. Moore \& J. A. Whitt (Eds.), Research in politics and society: 295-323. Greenwich CT: JAI Press.

Burt, R. S. 1983. Distinguishing relational contents. In R. S. Burt \& M. J. Minor (Eds.), Applied network analysis: 35-74. Beverly Hills, CA: Sage.

Burt, R. S. 2005. Brokerage and closure. New York: Oxford University Press.

Burt, R. S., \& Knez, M. 1995. Kinds of third-party effects on trust. Rationality and Society, 7: 255-292.

Burt, R. S., \& Knez, M. 1996. Trust and third-party gossip. In R. M. Kramer \& T. R. Tyler (Eds.), Trust in organizations: Frontiers of theory and research: 68-89. Thousand Oaks, CA: Sage.

Carley, K. M. 1991. A theory of group stability. American Sociological Review, 56: 331-354.
Clawson, J. 1980. Mentoring in managerial careers. In C. B. Derr (Ed.), Work, family, and the career: 144165. New York: Praeger.

Coleman, J. 1988. Social capital in the creation of human capital. American Journal of Sociology, 94: 95-120.

Coleman, J. 1990. Foundation of social theory. Cambridge, MA: Harvard University Press.

Cross, R., \& Sproull, L. 2004. More than answer: Information relationships for actionable knowledge. Organization Science, 15: 446-462.

Dawes, R. M. 1980. Social dilemmas. In M. R. Rosenzweig \& L. W. Porter (Eds.), Annual review of psychology, vol. 31: 169-193. Palo Alto, CA: Annual Reviews.

Drolet, A. L., \& Morris, M. W. 2000. Rapport in conflict resolution: Accounting for how face-to-face contact fosters mutual cooperation in mixed-motive conflicts. Journal of Experimental Social Psychology, 36: $26-50$.

Dunbar, R. I. M. 2004. Gossip in evolutionary perspective. Review of General Psychology, 8: 100-110.

Farh, J., Tsui, A. S., Xin, K., \& Cheng, B. 1998. The influence of relational demography and guanxi: The Chinese case. Organization Science, 9: 471-488.

Fehr, B. 2004. Intimacy expectations in same-sex friendships: A prototype interaction-pattern model. Journal of Personality and Social Psychology, 86: 265284.

Ferrin, D. L., Dirks, K. T., \& Shah, P. P. 2006. Direct and indirect effects of third-party relationships on interpersonal trust. Journal of Applied Psychology, 91: $870-883$.

Fiske, S. T., Cuddy, A. J. C., \& Glick, P. 2007. Universal dimensions of social cognition: Warmth and competence. Trends in Cognitive Sciences, 11(2): 77-83.

Fiske, S. T., \& Neuberg, S. L. 1990. A continuum of impression formation, from category-based to individuating processes: Influences of information and motivation on attention and interpretation. In $\mathrm{M}$. Zanna (Ed.), Advances in experimental social psychology: 1-74. San Diego: Academic Press.

Flynn, F. J. 2005. Identity orientations and forms of social exchange in organizations. Academy of Management Review, 30: 737-750.

Foa, U. G., \& Foa, E. B. 1974. Societal structures of the mind. Springfield, IL: Thomas.

Fox, A. 1974. Beyond contract: Work, power, and trust relations. London: Faber and Faber.

Freeman, L. C. 2004. The development of social network analysis: A study in the sociology of science. Vancouver: Empirical Press.

Fryxell, G. E., Dooley, R. S., \& Vryza, M. 2002. After the ink dries: The interaction of trust and control in US-based international joint ventures. Journal of Managerial Studies, 39: 865-886. 
Gibbons, D. 2004. Friendship and advice networks in the context of changing professional values, Administrative Science Quarterly, 49: 238-262.

Gibbons, D., \& Olk, P. M. 2003. Individual and structural origins of friendship and social position among professionals. Journal of Personality and Social Psychology, 84: 340-351.

Graen, G. B., \& Cashman, J. 1975. A role-making model of leadership in formal organizations: A development approach. In J. G. Hunt \& L. L. Larson (Eds.), Leadership frontiers: 143-165. Kent, OH: Kent State University Press.

Granovetter, M. 1973. The strength of weak ties. American Journal of Sociology, 78: 1360-1380.

Granovetter, M. 1985. Economic action and social structure: The problem of embeddedness. American Journal of Sociology, 91: 481-510.

Hausman, J. 1978. Specification tests in econometrics. Econometrica, 46: 1251-1271.

Hausman, J., Hall, B. H., \& Griliches, Z. 1984. Econometric-models for count data with an application to the patents-R and D relationship. Econometrica, 52: 909-938.

Heider, F. 1958. The psychology of interpersonal relations. New York: Wiley.

Heider, F. 1979. On balance and attribution. In P. Holland \& S. Leinhardt (Eds.), Perspectives on social network research: 11-24. New York: Academic Press.

Helliwell, J. F. 2005. Well-being, social capital and public policy: What's new? Paper presented at the Annual Meetings of the Royal Economic Society, Nottingham, U.K.

Hill, C. L. 1990. Cooperation, opportunism, and the invisible hand: Implications for transaction cost theory. Academy of Management Review, 15: 500514.

Hinds, P. J., Carley, K. M., Krackhardt, D., \& Wholey, D. 2000. Choosing work group members: Balancing similarity, competence, and familiarity. Organizational Behavior and Human Decision Performance, 81: $226-251$.

Hite, J. 2005. Evolutionary processes and paths of relationally embedded network ties in emerging entrepreneurial firms. Entrepreneurship Theory and Practice, 29: 113.

Hoffman, D., Griffin, M., \& Gavin, M. 2000. The application of hierarchical linear modeling to organizational research. In K. Klein \& S. Kozlowski (Eds.), Multilevel theory, research, and methods in organizations: 467-511. San Francisco: Jossey Bass.

Holste, J. S., \& Fields, D. 2005. The relationship of affect and cognition-based trust with sharing and use of tacit knowledge. Academy of Management Best Papers Proceedings: B1-B6.
House, J. S., Umberson, D., \& Landis, K. R. 1988. Structures and processes of social support. In W. R. Scott (Ed.), Annual review of sociology, vol. 14: 293-318. Palo Alto, CA: Annual Reviews.

Ingram, P., \& Roberts, P. W. 2000. Friendships among competitors in the Sydney hotel industry. American Journal of Sociology, 106: 387-423.

Jehn, K. A. 1995. A multimethod examination of the benefits and detriments of intragroup conflict. Administrative Science Quarterly, 40: 256-282.

Jehn, K., \& Shah, P. 1997. Interpersonal relationship and task performance: An examination of mediating processes in friendship and acquaintance groups. Journal of Personality and Social Psychology, 72: 775790.

Kadushin, C. 1982. Social density and mental health. In P.V. Marsden \& N. Lin (Eds.), Social structure and network analysis: 147-158. Beverly Hills, CA: Sage.

Kilduff, M., \& Krackhardt, D. 1994. Bringing the individual back in: A structural analysis of the internal market for reputation in organizations. Academy of Management Journal, 37: 87-108.

Kilduff, M., Tsai, W., \& Hanke, R. 2006. A paradigm too far? A dynamic stability reconsideration of the social network research program. Academy of Management Review, 31: 1031-1048.

Klein, K. J., Dansereau, F., \& Hall, R. J. 1994. Levels issues in theory development, data collection, and analysis. Academy of Management Review, 19: 195-229.

Krackhardt, D., \& Stern, R. N. 1988. Informal networks and organizational crises: an experimental stimulation. Social Psychology Quarterly, 51: 123-140.

Kram, K. E. 1985. Mentoring at work: Developmental relationships in organizational life. Glenview, IL: Scott, Foresman.

Kram, K. E., \& Isabella, L. 1985. Mentoring alternatives: The role of peer relationships in career development. Academy of Management Journal, 28: 110-132.

Kramer, R. M. 1999. Trust and distrust in organizations: Emerging perspectives, enduring questions. In J. T. Spence (Ed.), Annual review of psychology, vol. 50: 569-598. Palo Alto, CA: Annual Reviews.

Labianca, G., \& Brass, D. J. 2006. Exploring the social ledger: Negative relationships and negative asymmetry in social networks in organizations. Academy of Management Review, 31: 596-614.

Labianca, G., Brass, D. J., \& Gray, B. 1998. Social networks and perceptions of intergroup conflict: The role of negative relationships and third parties. Academy of Management Journal, 41: 55-67.

Larson, A. 1992. Network dyads in entrepreneurial settings: A study of the governance of exchange relationships. Administrative Science Quarterly, 37: 76-104.

Levin, D. Z., \& Cross, R. 2004. The strength of weak ties 
you can trust: The mediating role of trust in effective knowledge transfer. Management Science, 50: 1477-1490.

Lewicki, R. J., \& Bunker, B. B. 1996. Developing and maintaining trust in work relationships. In R. M. Kramer \& T. R. Tyler (Eds.), Trust in organizations: Frontiers of theory and research: 114-139. Thousand Oaks, CA: Sage.

Lewis, J. D., \& Weigert, A. 1985. Trust as a social reality. Social Forces, 63: 967-985.

Lin, N. 1999. Building a theory of social capital. Connections, 22(1): 28-51.

Lincoln, J. R., \& Miller, J.1979. Work and friendship ties in organizations: A comparative analysis of relational networks. Administrative Science Quarterly, 24: 181-199.

Mayer, R. C., Davis, J. H., \& Schoorman, F. D. 1995. An integrative model of organizational trust. Academy of Management Review, 20: 709-734.

McAllister, D. J. 1995. Affect- and cognition-based trust as foundations for interpersonal cooperation in organizations. Academy of Management Journal, 38: $24-59$.

McGrath, C. A., Vance, C. M., \& Grey, E. R. 2003. With a little help from their friends: Exploring the advice networks of software entrepreneurs. Creativity and Innovation Management, 12 : 2-10.

Messick, D., \& Brewer, M. 1983. Solving social dilemmas: A review. In L. Wheeler \& P. Shaver (Eds.), Review of personality and social psychology, vol. 4: 11-44. Beverly Hills, CA: Sage.

Mitchell, R. E., \& Trickett, E. J. 1980. Task force report: Social networks as mediators of social support. Community Mental Health Journal, 16 : 27-44.

Ng, K.Y., \& Chua, R.Y. J. 2006. Do I contribute more when I trust more? Differential effects of cognition- and affect-based trust. Management and Organization Review, 2: 43-66.

Nicholson, N., \& Johns, G. 1985. The absence culture and the psychological contract-Who's in control of absence? Academy of Management Review, 10: 397-407.

Podolny, J. M, \& Baron, J. N. 1997. Resources and relationships: Social networks and mobility in the workplace. American Journal of Sociology, 62: 673-693.

Podsakoff, P. M., MacKenzie, S. B., Lee, J., \& Podsakoff, N. P. 2003. Common method biases in behavioral research: A critical review of the literature and recommended remedies. Journal of Applied Psychology, 88: 879-903.

Polister, P. E. 1980. Network analysis and the logic of social support. In R. H. Price \& P. E. Polister (Eds.), Evaluation and action in the social environment: 69-87. New York: Academic Press.

Rempel, J. K., Holmes, J. G., \& Zanna, M. D. 1985. Trust in close relationships. Journal of Personality and Social Psychology, 49: 95-112.

Rotter, J. B. 1967. A new scale for the measurement of interpersonal trust. Journal of Personality, 35: 651665.

Rozin, P., \& Royzman, E. B. 2001. Negativity bias, negativity dominance, and contagion. Personality and Social Psychology Review, 5: 296-320.

Sahlins, M. D. 1972. Stone age economics. Chicago: Aldine-Atherton.

Schweizer, T. 1997. Embeddedness of ethnographic cases: A social networks perspective. Current Anthropology, 38: 739-760.

Seibert, S. E., Kraimer, M. L., \& Liden, R. C. 2001. A social capital theory of career success. Academy of Management Journal, 44: 219-327.

Sias, P. M., \& Cahill, D. J. 1998. From coworkers to friends: The development of peer friendships in the workplace. Western Journal of Communication, 62: 273-299.

Silver, A. 1990. Friendship in commercial society: Eighteenth-century social theory and modern sociology. American Journal of Sociology, 95: 1474-1504.

Sparrowe, R. T., \& Liden, R. C. 2005. Two routes to influence: Integrating leader-member exchange and social network perspectives. Administrative Science Quarterly, 50: 505-535.

Sparrowe, R. T., Liden, R. C., Wayne, S. J., \& Kraimer, M. L. 2001. Social networks and the performance of individuals and groups. Academy of Management Journal, 44: 316-325.

Stokes, J. P. 1985. The relation of social network and individual difference variables to loneliness. Journal of Personality and Social Psychology, 48: 981-90.

Stokes, J. P., \& Levin, I. 1986. Gender differences in predicting loneliness from social network characteristics. Journal of Personality and Social Psychology, 51: 1069-1074.

Suttles, G. D. 1970. Friendship as a social institution. In G. J. McCall, M. M. McCall, N. K. Denzin, G. D. Suttles, \& S. B. Kurth (Eds.), Social relationships: 95-135. Hawthorne, NY: Aldine.

Taylor, S. E. 1991. Asymmetrical effects of positive and negative events: The mobilization-minimization hypothesis. Psychological Bulletin, 110: 67-85.

Tichy, N., Tushman, M., \& Fombrun, C. 1979. Social network analysis for organizations. Academy of Management Review, 4: 507-520.

Totterdell, P., Wall, T., Holman, D., Diamond, H., \& Epitropaki, O. 2004. Affect networks: A structural analysis of the relationship between work ties and jobrelated affect. Journal of Applied Psychology, 89: 854-867.

Uzzi, B. 1996. The sources and consequences of embed- 
dedness for the economic performance of organizations: The network effect. American Sociological Review, 61: 674-698.

Uzzi, B., \& Gillespie, J. J. 2002. Knowledge spillover in corporate financing networks: Embeddedness and the firm's debt performance. Strategic Management Journal, 23: 595-618.

Verbrugge, L. M. 1977. The structure of adult friendship choice. Social Forces, 56: 576-597.

Webber, S. S., \& Klimosky, R. J. 2004. Client-project manager engagements, trust and loyalty. Journal of Organizational Behavior, 25: 997-1013.

Wellman, B. 1988. Structural analysis: From method and metaphor to theory and substance. In B. Wellman \& S. D. Berkowitz (Eds.), Social structures: A network approach: 19-61. Cambridge, U.K.: Cambridge University Press.

Wert, S. R., \& Salovey, P. 2004. A social comparison account of gossip. Review of General Psychology, 8: 122-137.

Williamson, O. E. 1993. Calculativeness, trust, and economic organization. Journal of Law and Economics, 36: $453-486$.

Wilson, J. M., Straus, S. G., \& McEvily, B. 2006. All in due time: The development of trust in computer-mediated and face-to-face teams. Organizational Behavior and Human Decision Processes, 99: 16-33.

Wiseman, J. P. 1986. Friendship: Bonds and binds in a voluntary relationship. Journal of Social Personality Relations, 3: 191-121.
Zelizer, V. A. 2005. The purchase of intimacy. Princeton, NJ: Princeton University Press.

Zucker, L. G. 1986. Production of trust: Institutional sources of economic structure. In B. M. Staw \& L. L. Cummings (Eds.), Research in organizational behavior, vol. 8: 53-111. Greenwich, CT: JAI Press.

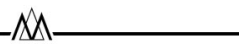

Roy Chua (yrc2101@columbia.edu) is currently completing his Ph.D. in management at Columbia Business School. His research interests include interpersonal trust, social networks, choice, and creativity. His dissertation explores how managers who give others autonomy and choice at work are perceived.

Paul Ingram (pi17@columbia.edu) is the Kravis Professor of Business at the Columbia Business School and the faculty director of the Columbia Senior Executive Program. He received his Ph.D. in management from Cornell University. His research examines the interdependence between institutions and network structure, and its implications regarding performance and change for individuals, organizations, and states.

Michael Morris (mwm82@columbia.edu) is the ChavkinChang Professor of Leadership at the Columbia Business School. He received his Ph.D. in psychology from the University of Michigan. His research examines the influence of culture and identity on cognition and behavior, as well as other aspects of decision making, negotiations, and social networks.

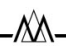

